\title{
Test of Anderson-Stuart model in sodium silicate glasses and the general Arrhenian conductivity rule in wide composition range
}

\section{(Teste do modelo de Anderson-Stuart em vidros silicatos de sódio e a regra geral da condutividade de Arrhenius numa ampla faixa de composições)}

\author{
M. L. F. Nascimento ${ }^{1}$, E. Nascimento ${ }^{2}$, W. M. Pontuschka ${ }^{2}$, M.Matsuoka $^{2}$, S. Watanabe ${ }^{2}$ \\ Department of Materials Engineering, Federal University of S. Carlos, S. Carlos, SP, 13565-905 \\ ${ }^{2}$ Institute of Physics, University of S. Paulo, S. Paulo, SP 05508-900 \\ pmlfn@iris.ufscar.br
}

\begin{abstract}
We collected and analyzed literature data on ionic conductivity $\sigma$ and activation energy $E_{A}$ in the binary sodium silicate system in a wide composition range. The Anderson and Stuart model has been considered to describe the decreasing tendency of activation energy $E_{A}$ with alkali concentration in this system. In this analysis were considered experimental parameters, such as shear modulus $G$ and relative dielectric permittivity $\varepsilon$. A general conductivity rule is found in 194 of 205 glasses, when one plots $\log \sigma v s$. $E_{A} / k_{B} T$, where $k_{B}$ is the Boltzmann constant and $T$ is the absolute temperature. This fact means that the arrhenian relation has universal uniqueness of form $\sigma=\sigma\left(\mathrm{E}_{\mathrm{A}}, \mathrm{T}\right)$ in wide $\mathrm{Na}_{2} \mathrm{O}$ composition range. The results also show that there is strong correlation by more than 19 orders of magnitude on conductivity with $E_{A} / k_{B} T$. An explanation for this behavior links ionic conductivity and microscopic structure. The problem of phase separation in this system is also considered.
\end{abstract}

Keywords: Glass, electrical properties, ionic conduction, Anderson-Stuart model.

\section{Resumo}

Foram colecionados e analisados dados da literatura sobre condutividade iônica $\sigma$ e energia de ativação de condução $E_{A}$, considerando o sistema binário silicato de sódio numa ampla faixa de composições. O modelo de Anderson e Stuart foi utilizado para descrever a tendência de decréscimo da energia de ativação $E_{A}$ com a concentração de álcalis neste sistema. Nesta análise foram considerados parâmetros experimentais tais como módulo de cisalhamento $G$ e permissividade dielétrica relativa $\varepsilon$. Uma regra geral de condutividade foi observada em 194 de 205 vidros analisados quando se plota log $\sigma v s . E_{A} / k_{B} T$, onde $k_{B} e ́$ a constante de Boltzmann e Té a temperatura absoluta. Isto significa que a relação de Arrhenius apresenta uma unicidade característica universal da forma $\sigma=\sigma\left(E_{A}, T\right)$ numa ampla faixa de composições $\left(\mathrm{Na}_{2} \mathrm{O}\right)$. Os resultados também mostraram que há uma forte correlação, por mais de 19 ordens de grandeza, da condutividade com o parâmetro $E_{A} / k_{B} T$. Uma explicação deste comportamento relaciona condutividade iônica e estrutura microscópica. O problema da separação de fases neste sistema também foi considerado.

Palavras-chave: vidro, propriedades elétricas, condução iônica, modelo de Anderson-Stuart.

\section{INTRODUCTION}

Glassy electrolytes are of particular importance because of their inherent advantages such as isotropic conductivity, ease of preparation, better thermal stability, the large available composition ranges which make them potential candidates for technological applications (new solid-state batteries, fuel cells, chemical sensors, "smart windows"), and also the search for an general theory of ion-transport in glassy materials. Despite considerable experimental and theoretical effort, the diffusion mechanism is not yet fully understood [1]. Numerous chemical and physical models have been proposed, and they vary from thermodynamics with principles in models for liquid electrolytes, such as the weak electrolyte model [2], to models based on solid state concepts such as the jump diffusion model [3], the strong electrolyte model [4], and the dynamic structure model [5].

The electrical conductivity in alkali silicate glasses have been found to increase with increasing the concentration of alkali ions [6]. This phenomenon is explained on the basis of an assumption that a progressive breakdown of the threedimensional glass network accompanied by the rupture of $\mathrm{Si}-\mathrm{O}$ bonds proceeds with an addition of alkali ions into the glass network, resulting in a lowering of the activation energy for ionic conduction. Attempts to correlate the variation of the activation energy with the onset of phase separations have been made. However, until recently it was not clear how the glass composition and/or the glass phase affect the activation energy $[6,7]$. 
Various models have been proposed for estimating the activation energy in alkali glasses and among them a model suggested by Anderson and Stuart [4] (A-S) is considered to be the most directly related to physically meaning parameters, such as ionic radii, relative dieletric permittivity and elastic modulus. But at the time of the A-S theory no much experimental data were available. For the present system, only Hakim and Uhlmann [8] had proposed modifications on the A-S model.

The A-S model has proved to be valid in many amorphous or crystallized oxides, and it is still applied [9-14]. However, it fails to explain complex behaviors [9]. Recent approaches for describing structure-conductivity-energy activation relations in ionic glasses were done, such as bond valence method [9], or a "general" conductivity rule [10]. Recently, Balaya et al. [11] used A-S model in lead silicate system, Jogad [12] in a glass-ceramics and Pan and Ghosh [13] in a lead bismuthate glass. A modification on A-S model was used by Roselieb and Jambon [14] to calculated activation energies in sodium aluminosilicate melts. But in none of previous studies were found relations about activation energy with composition in wide range, even in simple systems.

We have examined the extensive literature on glass conductivity and performed new experiments to determine the effect of sodium on the conductivity of silicate glasses. In order to understand the transport mechanism, it is therefore essential to find a connection between microscopic structure and ionic conductivity. Important correlations emerged between glass conductivity and composition.

The present paper will report on the ionic condutivities and activation energies of glasses in $\mathrm{Na}_{2} \mathrm{O}-\mathrm{SiO}_{2}$ system, with the purpose to correlate new proposals to activation energy with composition using experimental parameters data, such as shear modulus $G$ and relative dielectric permittivity $\varepsilon$. Also, a general finding, including different sodium silicate glass compositions, is obtained when one uses $\log \sigma v s . E_{\mathrm{A}} /$ $k_{B} T$. Thus, it is the aim of the present article to relate the patterns of ionic transport in glasses to some general aspects of ion transport in solids as they are evident from the authors' viewpoint.

\section{EXPERIMENTAL}

Some glass samples of composition $\mathrm{xNa}_{2} \mathrm{O} \cdot(1-\mathrm{x}) \mathrm{SiO}_{2}$ with $\mathrm{x}=30,35$, 40, 45 and $50 \mathrm{~mol} \%$ were prepared by melting (at $1200-1400{ }^{\circ} \mathrm{C}$ for $2-4 \mathrm{~h}$ in air) $\mathrm{SiO}_{2}$ and $\mathrm{Na}_{2} \mathrm{CO}_{3}$ in a Pt$10 \% \mathrm{Rh}$ crucible. All the samples obtained were examined by an optical microscope (Jenapol, Carl Zeiss) and found to be free of observable strains, cords, bubbles or inclusions. The chemical composition in some samples analyzed with ICP-AES (Inductively Coupled Plasma-Atomic Emission Spectrometry) indicated a deviation from batch composition of less than 1 mole\%. The glass transition temperatures $\left(\mathrm{T}_{\mathrm{g}}\right)$ were determined in air with a DSC (Differential Scanning Calorimetry Netzsch 404).
Specimens of about $10 \times 10 \times 1 \mathrm{~mm}^{3}$ were polished by hand grinding with a slurry of water (or kerosene for higher-alkali concentration specimens), and SiC powder of 600-800-1000 mesh, followed by polishing with water (or kerosene) an alumina powder between 2 and $5 \mu \mathrm{m}$, from Buehler. Silver electrodes were applied by silver paint to the two largest planes of each specimen.

The dc conductivity measurements were carried out at $25-400{ }^{\circ} \mathrm{C}$ in air with a dc two-electrode method. A pair of spring-loaded nickel rods was located in a vertical furnace tube to assure good contact between sample and electrode, and with windings run in opposite directions to eliminate electromagnetic fields due to heating current. Current measurements were made using a Keithley 610C electrometer $\left(10^{-1}-10^{-11} \mathrm{~A}\right.$ range), a $100 \mathrm{mV}$ Lambda voltage source, and an ECIL JR temperature controller.

The AC measurements were carried out in another furnace, using silver paint and Pt electrodes, a HP 4192A impedance analyzer with $100-200 \mathrm{mV}$ voltage applied in the frequency range $5 \mathrm{~Hz}-13 \mathrm{MHz}$. A ZView free-program was used for analysis results [15].

Both measurements were done in air atmosphere, with type $\mathrm{K}$ thermocouples as near possible from electrodes, and systems were calibrated. Electrical conductivities of glasses were measured at various temperatures, from room temperature up to $50{ }^{\circ} \mathrm{C}$ below $\mathrm{T}_{\mathrm{g}}$ (when applicable), and all samples were kept in a dessicator between measurements. More details can be found elsewhere [16].

\section{RESULTS}

Ionic conduction in glass is a thermally activated process of the mobile ions by surmounting a potential barrier $E_{A}$. Many data [17-82] were collected and compared with our results using dc and ac measurements (see Fig. 1).

In general dc conductivity is a bit higher than ac considering the same system (within one magnitude order of $\sigma$, at fixed temperature), mainly due to electrode effect. The measured ac conductivity consists of intrinsic conductivity of materials along with electrode resistance and electrode sample interface resistance. A detailed comparative analysis about dc and ac measurements was done elsewhere [16]. In fact, from these experiments it is clear that the electrical conductivity increases with the increasing of sodium ion concentration. As known for decades, the electrical conductivity $\sigma$ measured for all glass specimens was found to obey the Arrhenius relation (Eq. A):

$$
\log \sigma=\log \sigma_{0}-(\log e) E_{A} / k_{B} T
$$

where $\sigma_{0}$ is a constant, $k_{B}$ is the Boltzmann constant, $T$ is the absolute temperature and $E_{A}$ is the activation energy (enthalpy) for conduction. About Eq. A, up to now it was only considered in the simple form $\sigma=\sigma(T)$ for each glass specimen, as shown in Fig. 1. As will be presented below, 


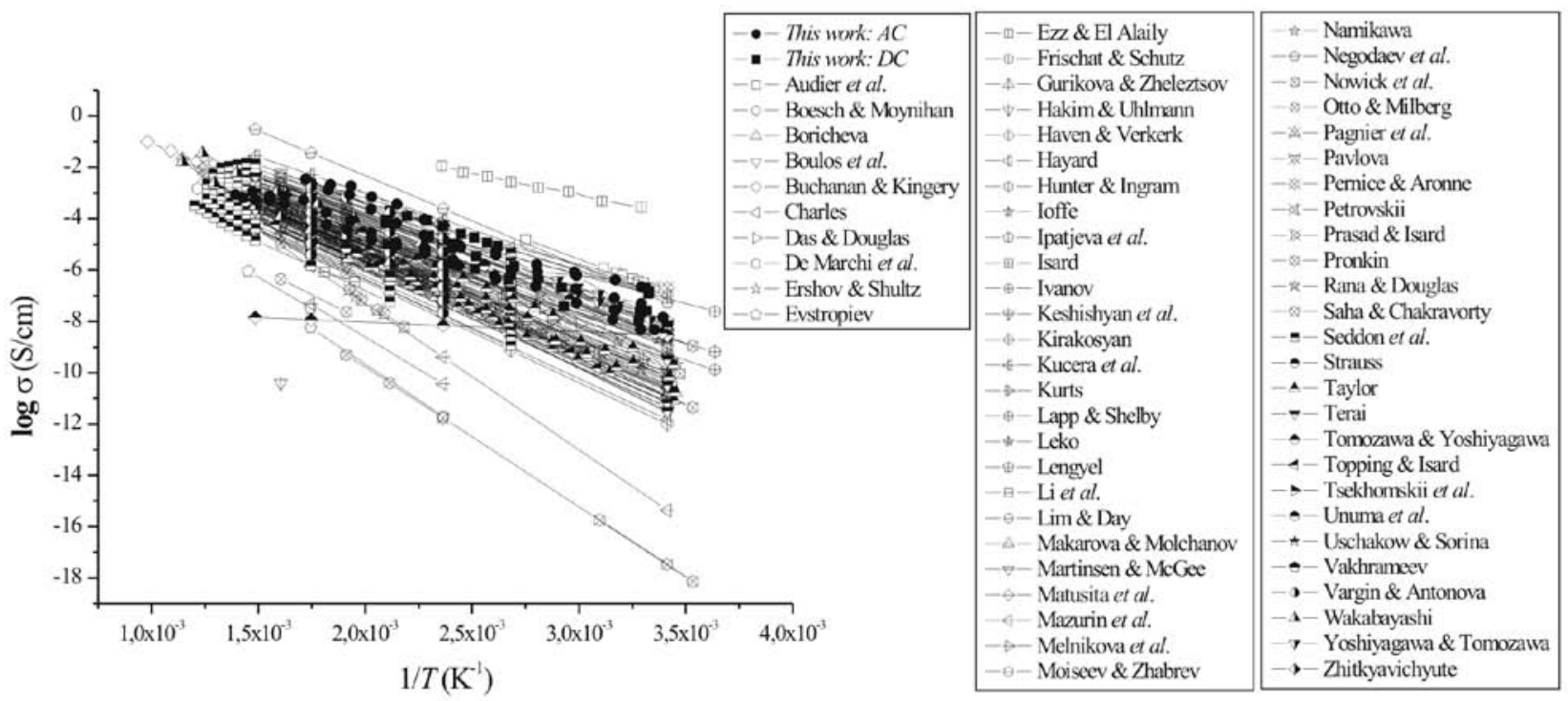

Figure 1: Arrhenian plots of ionic conductivities in 205 binary sodium silicate glasses in wide composition range [17-82]. [Figura 1: Gráficos de Arrhenius de condutividades iônicas em 205 vidros binários silicatos de sódio numa ampla faixa de composições [17-82].]

Eq. A would be more usefull when one considers $\sigma=\sigma$ $\left(\mathrm{E}_{\mathrm{A}}, \mathrm{T}\right)$, what means in fact a more general rule.

Many experimental works on conductivity have been published over years, basically searching for highest conductivity values or presenting theories that apply better in one than in another system. However, there is a disparity between experimental data on similar glasses from different authors, as shown in Fig. 1. In many works [17-82] one could see omissions over simple characteristics as kind and electrode influence, tension applied, surface preparation and conditions, heat treatments, phases involved, etc.

The dc mode is easier, and the more frequent experimental procedure. Many authors in those cited [17-82] presented data rather on this simple experiment than the more precise ac mode. Fig. 1 shows the increasing tendency of conductivity $\sigma$ with increase of temperature, as expected, but no more general conclusions could be obtained from this graphic when one uses $\log \sigma$ Vs. $1 / T$.

Better results frequently come from impedance (ac) measurements [16], but good data could still be measuring by dc mode, taking some precautions. The authors did not note any considerable difference from conductivity values using these two measurement modes [16]. But, from a statistical view point, it is interesting to use all data available to assess a general behaviour (as described below).

In fact, the variation in values of activation energies implies in different experimental procedures. For common glasses at room temperatures the conductivities are lower than $10^{-10} \mathrm{ohm} . \mathrm{m}$, approaching the limit of available measuring apparatus. At high alkali content, the samples are hygroscopic, and special care on preparation procedures must be exercised. Observed differences in the activation energies seem likely to be associated with differences in the chemical and/or structural states and also the thermal history of the glass samples. In $\mathrm{Na}_{2} \mathrm{O}-\mathrm{SiO}_{2}$ composition system, a futher difference could arise from the discussion on effects related to phase separation [7].

\section{DISCUSSION}

\section{The Anderson-Stuart model}

Despite differences in the activation energies observed by different investigators, a number of common trends are seen in those data of Fig. 1. Perhaps most important is the decrease in activation energy with increasing sodium concentration. It is interesting, therefore, to see whether such behaviour can be predicted from a model proposed by Anderson and Stuart [4]. In this 'classical' model, the activation energy for conduction may be divided in two parts: the electrostatic binding energy of the original site $E_{b}$, and the strain energy, $E_{s}$, required to move an ion from one site to another. $E_{b}$ describes the coulombic forces acting on the ion as it moves away from its charge-compensating site, and $E_{s}$ describes the mechanical forces acting on the ion as it dilates the structure sufficiently to allow the ion to move between sites. The basic idea is that an ion (in this case $\mathrm{Na}^{+}$) makes a simple jump from one site to another, and passes through a 'doorway' which opens as it passes through, where cations sites require only the presence of non-bridging oxygens (Eq. B).

$$
E_{A}=\frac{\beta z z_{\mathrm{O}} e^{2}}{\varepsilon\left(r_{\mathrm{Na}}+r_{\mathrm{O}}\right)}+4 \pi G r_{\mathrm{D}}\left(r_{\mathrm{Na}}-r_{\mathrm{D}}\right)^{2}
$$


where $z$ and $z_{O}$ are the valence numbers of the mobile ion and the fixed counterion - in this cases sodium and oxygen, respectively, $r_{\mathrm{Na}}$ and $r_{\mathrm{O}}$ are the corresponding Pauling ionic radii for $\mathrm{Na}^{+}$and $\mathrm{O}^{2-}, e$ is the electronic charge, and $r_{\mathrm{D}}$ is the effective radius of the (unopened) doorway.

The parameters of interest in the A-S model are the elastic modulus $(G)$, a 'Madelung' constant $(\beta)$, which depends on how far apart the ions are, and the relative dielectric permittivity $(\varepsilon)$, which indicates the degree of charge neutralization between the ion and its immediate neighbours. Martin \& Angell [83] have provided a visualization of the energetics of the conduction process in an ionic conducting glass. McElfresh \& Howitt [84] suggested a modification on $E_{s}$ term, where they include the jumping distance $\lambda$ as a better parameter (Eq. C).

$$
E_{A}=\frac{\beta z z_{\mathrm{O}} e^{2}}{\varepsilon\left(r_{\mathrm{Na}}+r_{\mathrm{O}}\right)}+4 \pi G \lambda\left(r_{\mathrm{Na}}-r_{\mathrm{D}}\right)^{2}
$$

Two considerations are proposed here: $a$ ) One is related with shear modulus $G$. Available $G$ data decrease slightly with increasing $\mathrm{Na}_{2} \mathrm{O}$ mole\% concentration, confirming what was just estimated by A-S [4], and present on Fig. 2. b) The other is related to the experimental relative dielectric permittivity $\varepsilon$, that showed small increase with increasing $\mathrm{Na}_{2} \mathrm{O}$ mole\% concentration (see Fig. 3). At least, we consider $\beta$ (Eq. D) as done by Anderson and Stuart [4]:

$$
\beta=\frac{2.1-r_{\mathrm{Na}}}{3.5}
$$

where the $r_{\mathrm{Na}}$ value is given in $\AA$.

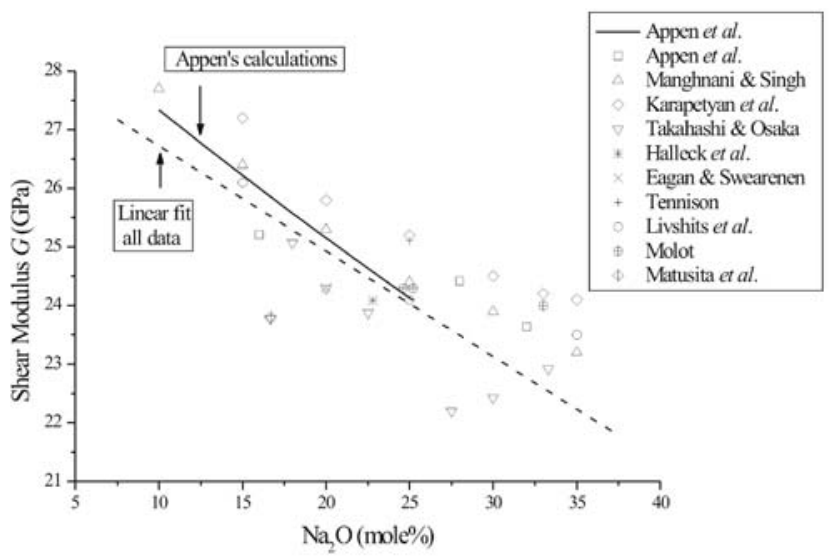

Figure 2: Experimental shear modulus ( $G$, in $\mathrm{GPa}$ ) of $\mathrm{Na}_{2} \mathrm{O}-\mathrm{SiO}_{2}$ system [85-94]. Fit on all data (dashed line). Note that data follows Appen's theoretical calculations tendency (full line).

[Figura 2: Módulo de cisalhamento experimental ( $G$, em GPa) do sistema $\mathrm{Na}_{2} \mathrm{O}-\mathrm{SiO}_{2}$ [85-94]. Ajuste linear em todos os dados (linha tracejada). Notar que os dados seguem a tendência de cálculos teóricos de Appen (linha cheia).]

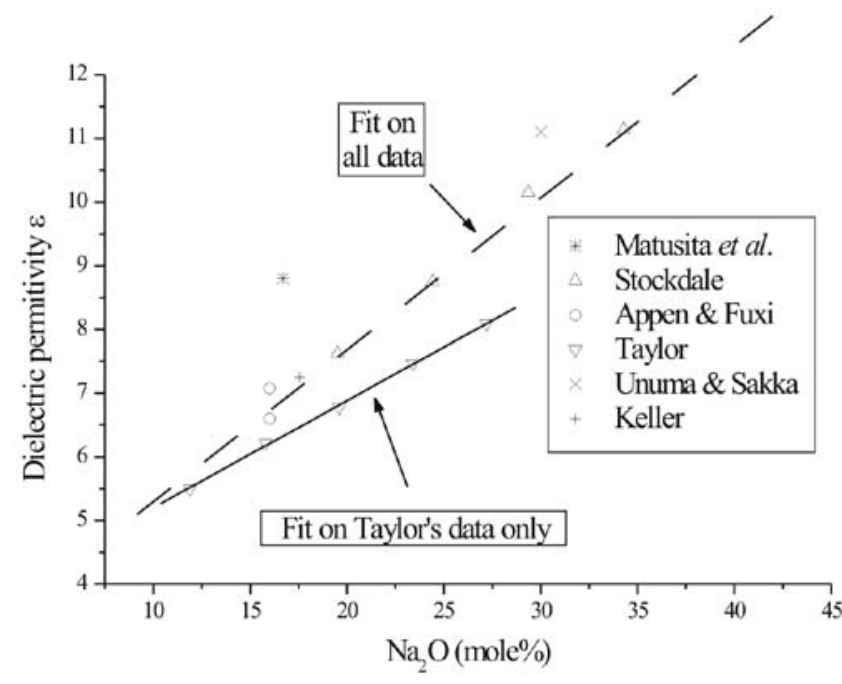

Figure 3: Experimental relative dielectric permittivity values $(\varepsilon)$ of $\mathrm{Na}_{2} \mathrm{O}-\mathrm{SiO}_{2}$ system [95-99] considering all data (dashed line) or only Taylor's data (full line).

[Figura 3: Valores experimentais da permissividade dielétrica relativa (ع) do sistema $\mathrm{Na}_{2} \mathrm{O}-\mathrm{SiO}_{2}$ [95-99] considerando todos os dados (linha tracejada) ou somente considerando os dados de Taylor (linha cheia).]

Hakim and Uhlmann [8] proposed a modification on A-S model. Estimating the change in strain energy with concentration and type of alkali, they assumed that $r_{\mathrm{D}}$ varies as $\Delta r_{\mathrm{D}} / r_{\mathrm{D}}=1 / 3\left(\Delta V / V_{0}\right)$, where $V_{0}$ is the molar volume of $\mathrm{SiO}_{2}$, and $\Delta$ denotes the change in the respective quantities on addition of the alkali.

In this work the authors considered three assumptions:

i) fixed $r_{\mathrm{D}}$ fitting all data, as suggested by A-S theory, just for comparison;

ii) $\Delta r_{\mathrm{D}} / r_{\mathrm{D}}=1 / 3 \Delta n / n_{0}$, where $n_{0}$ is $\mathrm{SiO}_{2}$ mole\% concentration. In this adjustment $r_{\mathrm{D}}$ had a fixed value of $0.6 \AA$ for $18 \mathrm{Na}_{2} \mathrm{O} \cdot 82 \mathrm{SiO}_{2}$ mole\% composition. From this one could find $r_{\mathrm{D}}$ versus composition to vary from $0.37 \AA<r_{\mathrm{D}}<0.72 \AA$. In this form the minimum $r_{\mathrm{D}}$ value is near that used by Hakim and Uhlmann [8], and the maximum $r_{\mathrm{D}}$ value is a bit higher than used by Anderson and Stuart [4]. The fitting parameter choiced was the oxygen radius $r_{\mathrm{O}}$.

iii) $\lambda$ fitting all data, following McElfresh \& Howitt's suggestion [84] (Eq. C). In this case we consider also $r_{D}$ as a fitting parameter, just for comparison.

It is recognized that these assumptions of a similitude of form may provide an inadequate description of the change in $r_{\mathrm{D}}$ (and $\lambda$, when used) with alkali concentration, but it seems to represent only an approximation. For this model, no intensive numerical calculation is required.

From Fig. 2, the shear modulus $G$ from many authors [85-94] showed a small decrease with increasing sodium composition, but there is an evident scattering. In this work we followed a linear fit close the Appen's calculations [85], which suggested a linear decrease of $G$ with increasing 
sodium composition $n$ in sodium silicate system (Eq. E):

$$
\mathrm{G}=\mathrm{G}_{0}-\frac{\mathrm{dG}}{\mathrm{dn}} \mathrm{n}
$$

where $R^{2}=0.68$ is the correlation factor, $\mathrm{G}_{0}=28.52 \pm 0.57$ $\mathrm{GPa}$ and dG / dn $=(0.179 \pm 0.024) \mathrm{GPa} / \mathrm{mole} \%$.

From Fig. 3, the relative dielectric permittivity $\varepsilon$ from many authors [95-99] showed a small and monotonically increases with increasing sodium composition, with not so evidently scattering as in shear modulus $G$, but show two data sets. In this work we followed Taylor's data [97], which suggested a linear increase of $\varepsilon$ with increasing sodium composition $n$ in this system (Eq. F):

$$
\varepsilon=\varepsilon_{0}+\frac{\mathrm{d} \varepsilon}{\mathrm{dn}} \mathrm{n}
$$

where $R^{2}=0.999, \varepsilon_{0}=3.519 \pm 0.058$ and $\mathrm{d} \varepsilon / \mathrm{dn}=(0.1681 \pm$ $0.0029) / m o l e \%$, just considering Taylor's data.

The variation of activation energy $E_{A}$ with $\mathrm{Na}_{2} \mathrm{O}$ mole\% composition over a hundred glasses is shown in Fig. 4. In the first case were fixed radii values as done by A-S $\left(r_{\mathrm{Na}}=0.95\right.$ $\AA$ and $r_{\mathrm{O}}=1.4 \AA$ dotted line). The fitting parameter was the doorway radius, that resulted in $r_{D}(0.573 \pm 0.027) \AA$. In the second assumption the oxygen radius was fitted, giving $\mathrm{r}_{\mathrm{O}}(1.446 \pm 0.054) \AA$ with $r_{\mathrm{Na}}=0.95 \AA$ fixed, and considering $r_{\mathrm{D}}$ slightly dependent on $\mathrm{SiO}_{2}$ mole\% composition. Third assumption showed a high 'doorway' radius value using it as the fitting parameter, giving $r_{\mathrm{D}}=(0.798 \pm 0.008) \AA$ and considering the jumping distance $\lambda=3.5 \AA$ as a fixed value (dashed line). On assumptions $i$, ii and iii were used experimental shear modulus $G$ considering all data (Fig. 2) and the relative dielectric permittivity $\varepsilon$ only from Taylor's experimental values (Fig. 3).

The A-S model using experimental $G$ and $\varepsilon$ values is good for finding close values, but not at low (superestimated) $\mathrm{Na}_{2} \mathrm{O}$ mole $\%$ concentrations. If one fits these data considering McElfresh \& Howitt [84] suggestion (Eq. C), with $\lambda=3.5 \AA$, the result would be near the same of assumption $i$, but with a considerable increase in the $r_{\mathrm{D}}$ value.

Besides appreciable scatter, effects of glass composition on $E_{\mathrm{A}}$ could be parametrized by A-S theory. Even, this model could be interesting to apply in sodium silicate glasses to preview the amount of $E_{A}$ with $\mathrm{Na}_{2} \mathrm{O}$ composition considering non-separated glassy samples.

The adjustment for activation energy $E_{A}$ in Fig. 4 was performed using a Levenberg-Marquardt non-linear fitting [100]. It is surprinsigly that only one simple theory could adjust to a lot of data from several authors with different glass preparation processes in a wide range of compositions. The analysis using experimental relative dielectric permittivity $\varepsilon$ showed more influence on A-S theory than using shear modulus $G$, because $E_{b}>E_{s}$ in all composition range.

Still about Fig. 4, despite differences in the activation energies observed by different investigators, including different experimental procedures, a number of common trends are seen on these data. In fact, results obtained on $r_{\mathrm{Na}}$ and $r_{\mathrm{O}}$ are close to those presented in ref. [4], of $0.95 \AA$ and $1.4 \AA$, respectivally.

The sodium silicate system is know to be phase separated

\begin{tabular}{|c|c|}
\hline ㄸ & Enz\& El Alaily \\
\hline (i) & Frischat \& Schutz \\
\hline 4 & Gurikova \& Zheleztsov \\
\hline$\nabla$ & Hakim \& Uhlmann \\
\hline$\oplus$ & Haven \& Verkerk \\
\hline 4 & Hayard \\
\hline ه & Hunter \& Ingram \\
\hline$=$ & loffe \\
\hline ه & Ipatjeva et al. \\
\hline & Isard \\
\hline$\theta$ & Ivanov \\
\hline & Keshishyan et al. \\
\hline 4 & Kirakosyan \\
\hline 4 & Kucera et al. \\
\hline & Kurts \\
\hline$\oplus$ & Lapp \& Shelby \\
\hline \pm & Leko \\
\hline 由 & Lengyel \\
\hline E & Liet al. \\
\hline$\theta$ & Lim \& Day \\
\hline & Makarova \& Molchano \\
\hline & Martinsen \& McGee \\
\hline & Matusita et al. \\
\hline & Mazurin et al. \\
\hline & Melnikova et al. \\
\hline & Moiseev \& Zh \\
\hline
\end{tabular}

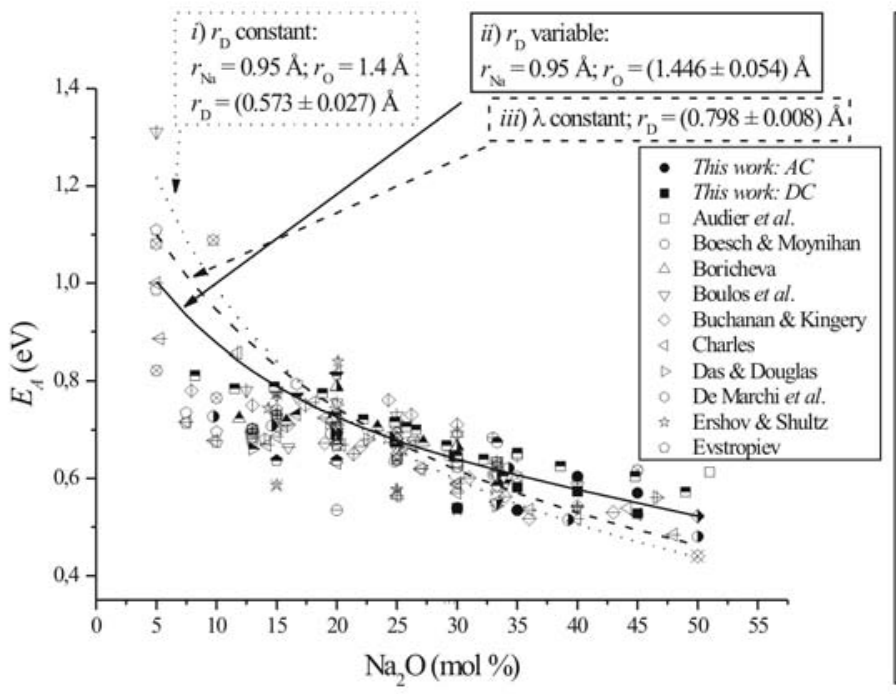

\begin{tabular}{|c|c|}
\hline$\#$ & Namikawa \\
\hline$\theta$ & Negodaev et al. \\
\hline a & Nowick et al. \\
\hline (3) & Otto \& Milberg \\
\hline « & Pagnier et al. \\
\hline \# & Pavlova \\
\hline$\%$ & Pernice \& Aronne \\
\hline$\star x$ & Petrovskii \\
\hline Ix & Prasad \& Isard \\
\hline ब & Pronkin \\
\hline * & Rana \& Douglas \\
\hline ब & Saha \& Chakravorty \\
\hline$=$ & Seddon et al. \\
\hline - & Strauss \\
\hline$\Delta$ & Taylor \\
\hline$\nabla$ & Terai \\
\hline$\leftrightarrow$ & Tomozawa \& Yoshiyagawa \\
\hline 4 & Topping \& Isard \\
\hline$\Rightarrow$ & Tsekhomskii et al. \\
\hline 0 & Unuma et al. \\
\hline * & Uschakow \& Sorina \\
\hline - & Vakhrameev \\
\hline - & Vargin \& Antonova \\
\hline $\mathbf{a}$ & Wakabayashi \\
\hline ' & Yoshiyagawa \& Tomozawa \\
\hline • & Zhitkyavichyute \\
\hline
\end{tabular}

Figure 4: Non-linear fit on activation energies (205 glasses from many authors [17-82]) of $\mathrm{Na}_{2} \mathrm{O}_{-} \mathrm{SiO}_{2}$ system considering assumptions $i\left(r_{\mathrm{D}}\right.$ constant, dotted line), ii ( $r_{\mathrm{D}}$ variable, full line) and iii ( $\lambda$, dashed line).

[Figura 4: Ajuste não-linear das energias de ativação (considerando 205 vidros de diversos autores [17-82]) do sistema $\mathrm{Na}_{2} \mathrm{O}$-SiO ${ }_{2}$ admitindo as suposições $i\left(r_{D}\right.$ constante, linha pontilhada), ii ( $r_{D}$ variável, linha cheia) e iii ( $\lambda$, linha tracejada).] 
over an appreciable range of composition (from almost pure silica to about $20 \mathrm{Na}_{2} \mathrm{O}$ mole\%), and its immiscibility boundary as well as its phase separation characteristics have been determined [7]. Phase separation has been shown to play a major role in controlling the conductivity properties of glasses. In many cases the morphology of the glass is far more importante than the bulk composition in determining this property [7]. Ionic diffusion could involve mass transport over extended distances; so it is particularly sensitive to changes in morphology. But the results of activation energies $E_{A}$ against $\mathrm{Na}_{2} \mathrm{O}$ mole\% composition in Fig. 4 show to be not strongly dependent on morphology of the sample within the immiscibility sodium silicate gap. However, Hakim \& Uhlmann [8] verified that by transmission electron microscopy that compositions of 5, 20 and $25 \mathrm{Na}_{2} \mathrm{O}$ mole\% were not phase separated on an observable scale, while that of 12.5 and $15 \mathrm{Na}_{2} \mathrm{O}$ mole\% composition indicated extensive separation. Then, it is interesting to note that data on Fig. 4 include results on glasses that were observably phase separated, and others which are not, among others with no indication. Briefly, activation energy $E_{A}$ of sodium silicate glasses seems to vary smoothly with composition, not so abruptly as Hakim \& Uhlmann have discussed [8], neither as Haven \& Verkerk have measured [32].

At high alkali content, the samples are hygroscopic, and special precautions in the preparation and measuring procedures must be taken to ensure the absence of surface or bulk proton conduction (from water content). These processes would lead to higher $\sigma$ conductivities, and consequently lower $E_{A}$ activation energies. While the origin of the scatter in the various reported values of the activation energy $E_{A}$ cannot now be identified, a comparison of the different data sets provides a feelling for the accuracy without detailed specification of their chemical and structural states. In the $\mathrm{Na}_{2} \mathrm{O} \cdot 3 \mathrm{SiO}_{2}$ system Takata et al. [101] observed that the conductivity-water content relation is similar to that observed in the "mixed-alkali" effect, and suggested a similar interaction between $\mathrm{Na}^{+}$and water $\left(\mathrm{H}^{+}\right.$or $\left.\mathrm{H}_{3} \mathrm{O}^{+}\right)$.

Results also show that $E_{b}$ is higher than $E_{s}$ in all composition range, similar as presented by Anderson \& Stuart. It is interesting to note that $E_{b}$ dependence with $\mathrm{Na}_{2} \mathrm{O}$ content is related to relative dielectric permittivity $\varepsilon$, which increases with sodium concentration. Values of relative permittivity $\varepsilon$ presented by Taylor [97] are close to A-S. The major difference between assumptions $i$, ii and iii with A-S theoretical values are firstly related to $\varepsilon$. Then the doorway radius $r_{\mathrm{D}}$ and the jump distance $\lambda$ must have only strong influence on glass systems that present major influence on $E_{s}$.

\section{The general conductivity rule}

Extensive studies have recently been made for obtaining a general equation from the standpoint of glass structure. For example, Doi [10] presented 17 different glasses (not mentioned) that follows an 'universal' conductivity rule.
Swenson \& Börjesson [102] proposed a common cubic scaling relation of $\sigma$ with the expansion volumes of the networking forming units in salt-doped and -undoped glasses. This fact suggested that the glass network expansion, which is related to the available free volume, is a key parameter determining the increase of the high ionic conductivity in some types of fast ion conducting glasses.

According to Adams \& Swenson [9], the ion conduction should be determined by the ionic motion within an infinite pathway cluster. For various silver ion conducting glasses [103-104], it was found that the cubic root of the volume fraction $F$ of infinite pathways for a fixed valence mismatch threshold is closely related to both the absolute conductivity and the activation energy of the conduction process, Eq. G:

$\log \sigma T \propto \sqrt[3]{F}=\log \sigma_{0}^{\prime}-(\log e) E_{A} / k_{B} T$

where $\sigma_{0}{ }^{\prime}$ is the pre-exponential factor (in $\mathrm{K} \cdot \mathrm{S} / \mathrm{cm}$ ).

More recently, Nascimento and Watanabe [105] verified this general finding in binary borate glasses, considering both Eqs. A and G. This paper aims to present new results considering just binary sodium silicate system.

Fig. 5 shows arrhenian plots of $\sigma$ for 205 sodium silicate glasses, from $x=5$ to $50 \mathrm{~mol} \%$, as indicated), ranging from near $10^{\circ} \mathrm{S} / \mathrm{cm}$ to $10^{-18} \mathrm{~S} / \mathrm{cm}$ between $20^{\circ} \mathrm{C}$ to $450{ }^{\circ} \mathrm{C}$. The range of activation energy $E_{A}$ lie between 0.45 and $1.35 \mathrm{eV}$ in all glasses studied, as indicated in Fig. 4. These data were compared with the general equation for $\sigma_{0}=50 \mathrm{~S} / \mathrm{cm}$ in Eq. A. This general equation, following Doy's sense, appears in Fig. 5 as a dashed line, and the dotted lines are the upper and lower limits within one magnitude order. Some glasses do not obey the general arrhenian finding, but they are exceptions that the authors included to get a statistical viewpoint.

According to Fig. 5, considering so many different binary sodium silicate glasses, is remarkable the strong correlation between $\sigma$ with $E_{\mathrm{A}}$ and $T$. It is interesting to note that the increase in ionic conductivity with alkali content is almost entirely due to the fact that the activation energy $E_{A}$ required for a cation jump decreases, as presented in Fig. 4. Thus, the term $\sigma_{0}$ in Eq. A is largely unaffected upon alkali content.

The main fact is that $\sigma$ lies on a single general curve in various sodium silicate glasses, whose conductivities differ by more than 19 orders of magnitude and within scatters of just one order of magnitude in $94.6 \%$ of the glass systems considered. Also is important to note the wide composition range involved. Therefore, if one measure $\sigma$ at some temperature, it is possible to estimate $E_{A}$ from Eq. A considering $\sigma_{0}=50 \mathrm{~S} / \mathrm{cm}$, and achieve a rough sketch of $\sigma$ at different temperatures. Or, if $E_{A}$ is obtained by some experimental or theoretical technique, ionic conductivity can be calculated.

Another general curve, following Eq. G and considering some binary sodium silicate glasses, resulted in the same general behaviour [106], as cited above. The pre- 

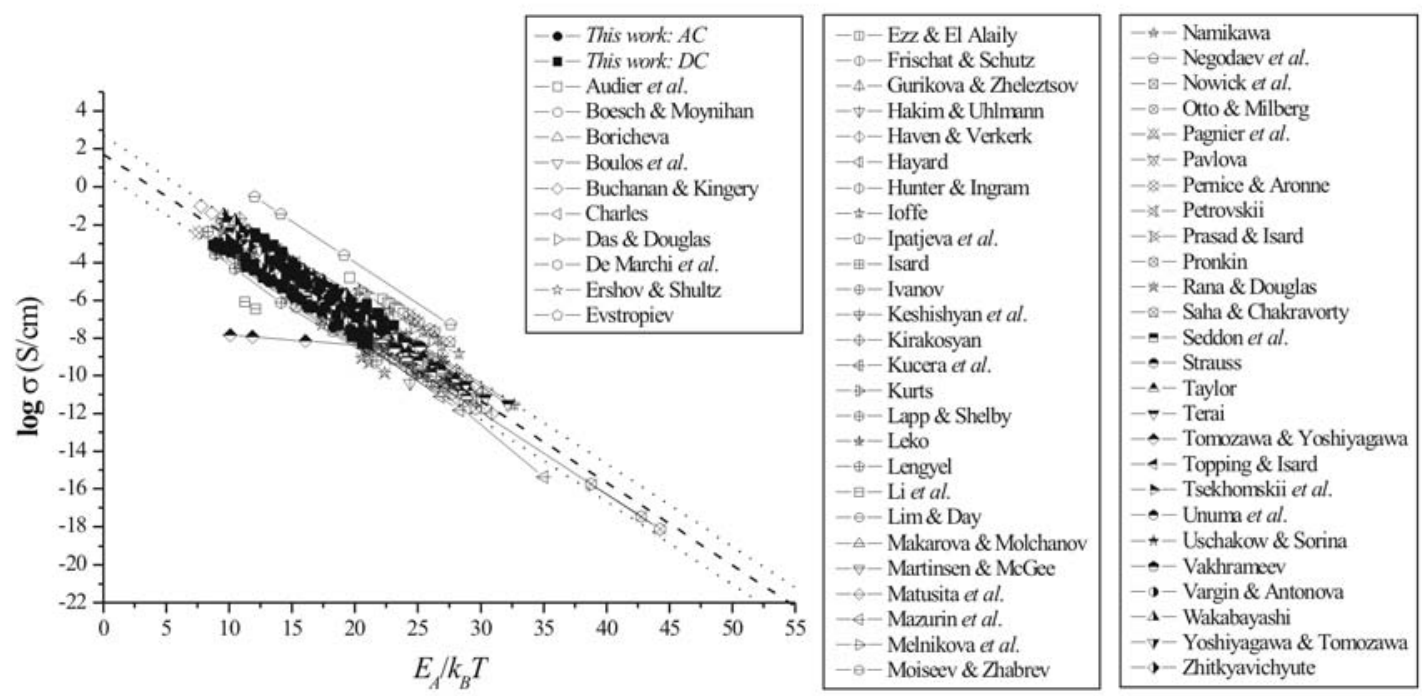

Figure 5: Arrhenian plots of ionic conductivities [17-82] in 205 binary sodium silicate glasses. The dashed line is the general curve, Eq. A, with $\sigma_{0}=50 \mathrm{~S} / \mathrm{cm}$, and the dotted lines correspond to one order of magnitude higher or lower than Eq. A.

[Figura 5: Gráficos de Arrhenius das condutividades ionicas [17-82] considerando 205 vidros binários silicatos de sódio. A linha tracejada corresponde à curva geral, Eq. A, onde $\sigma_{0}=50 \mathrm{~S} / \mathrm{cm}$, e as linhas pontilhadas correspondem à uma ordem de grandeza maior ou menor do que a expressa pela Eq. A.]

exponential value was $\sigma_{0}^{\prime}=50000 \mathrm{~K} \cdot \mathrm{S} / \mathrm{cm}$, considering the same conductivity data of Fig. 5. The conclusions for this case also follows the above described considering Eq. A. In resume, the most important fact is that in Fig. 5 the scattered data by glasses of different compositions is unified by the single general Eq. A. The fact that $\sigma$ lies on this single arrhenian straight line for many ion-conducting glasses means that ionic conductivity is governed mainly by $E_{A}$. All these compositions fall into an identifiable pattern where conductivity is related to structure, in the form expressed by the "pathway volumes" of Adams and Swenson [107].

Further studies on other binary alkali oxide glasses as presented on Fig. 5 would refuse or recognize this general finding, to gain further insight into the nature of ion dynamics in glass.

\section{CONCLUSIONS}

A modified Anderson-Stuart model for sodium-silica glass system investigated fits reasonable well experimental data in the range of 5 up to $50 \mathrm{Na}_{2} \mathrm{O}$ (mole\%), describing the tendency of lowering the activation energy with increasing $\mathrm{Na}_{2} \mathrm{O}$ composition. From this model, no intensive numerical calculation was required. In spite of minor discrepancies between dc and ac values and other experimental data, the conductivities are of same order of magnitude and could be compared with theory. The departure in the low percentage of $\mathrm{Na}_{2} \mathrm{O}$ is due to phase separation, as known in literature. The reasonable agreement between theory and experiment tells that there is a stronger contribution of coulomb-like interaction between non-bridging oxygen and sodium, more than elastic strain energy. Taking into account the experimental shear modulus $G$, the relative dielectric permittivity $\varepsilon$ and variable doorway radius $r_{\mathrm{D}}$ values (from 0.37 to $0.72 \AA$ ), for the first time good fits to experimental data were obtained. It was show further that the relative dielectric permittivity $\varepsilon$ (that presented linear increasing with $\mathrm{Na}_{2} \mathrm{O}$ composition) has giving more influence on fitting than $G$ in sodium silicate glass system. Considering A-S theory, sodium silicate conducting glasses fall into an identifiable pattern where conductivity is related to chemical composition. It is important to note that A-S model is essentially a single-particle approach. A general Arrhenius straight line is obtained using $\log \sigma v s . E_{A} / k_{B} T$ in this binary silicate system. This fact means that $\sigma$ is governed mainly by $E_{A}$, and $E_{A}$ is directly related to glass structure.

\section{ACKNOWLEDGEMENTS}

The authors acknowledge Brazilian agencies RHAE and CNPq for grant, Dr. E. D. Zanotto (UFSCar, Brazil) and Dr. V. M. Fokin (Vavilov State Optical Institute, Russia) for valuable suggestions. Special thanks to Dr. R. Muccillo (IPEN, Brazil) for measurements on ac conductivities and helpful assistance.

\section{REFERENCES}

[1] C. A. Angell, Ann. Rev. Phys. Chem. 43, 1 (1992) 693.

[2] D. Ravaine, J. -L. Souquet, Phys. Chem. Glasses 18, 2 (1977) 27.

[3] K. Funke, Prog. Solid State Chem. 22, 2 (1993) 111.

[4] O. L. Anderson, D. A. Stuart, J. Am. Ceram. Soc 37, 12 (1954) 573. 
[5] A. Bunde, M. D. Ingram, P. Maass, J. Non-Cryst. Solids 172/174 (1994) 1222.

[6] R. J. Charles. J. Am. Ceram. Soc 49, 2 (1966) 55.

[7] W. Haller, D. R. Blackburn, J. H. Simmons, J. Am. Ceram. Soc. 57, 3 (1974) 120.

[8] R. M. Hakim, D. R. Uhlmann, Phys. Chem. Glasses 12, 5 (1971) 132.

[9] S. Adams, J. Swenson, Phys. Chem. Chem. Phys. 4, 14 (2002) 3179.

[10] A. Doi. J. Mater. Sci. 39, 22 (2004) 6827.

[11] P. Balaya, V. K. Shrikhande, G. P. Kothiyal, P. S. Goyal, Curr. Sci. 86, 4 (2004) 553.

[12] M. S. Jogad, Mater. Lett. 54, 4 (2002) 249.

[13] A. Pan, A. Ghosh, Phys. Rev. B 62, 5 (2000) 3190.

[14] K. Roselieb, A. Jambon. Geochim. Cosmochim. Acta 66, 1 (2002) 109.

[15] Zplot ${ }^{\circledR} / Z v i e w$ for Windows (http://www.scribner.com).

[16] M. L. F. Nascimento, M.Sc. Dissertation, University of S. Paulo (2000) in Portuguese.

[17] M. Audier, D. Ravaine, J. -L. Souquet, C. R. Acad. Sci. C 282, 11 (1976) 499.

[18] L. P. Boesch, C. T. Moynihan, J. Non-Cryst. Solids 17, 1 (1975) 44.

[19] V. N. Boricheva, Thesis, Leningrad (1956).

[20] E. N. Boulos, A. V. Lesikar, C. T. Moynihan, J. NonCryst. Solids 45, 3 (1981) 419.

[21] R. C. Buchanan, W. D. Kingery, Compt. Rend.VII Cong. Int. Verre, Bruxelles, 2 (1965) p. 368.

[22] R. J. Charles, J. Am. Ceram. Soc. 49, 2 (1966) 55.

[23] C. R. Das, R. W. Douglas, Phys. Chem. Glasses 8, 5 (1967) 178.

[24] G. De Marchi, P. Mazzoldi, A. Miotello, Proc. XV Int. Cong. Glass, Leningrad, 2a (1989) 231.

[25] O. S. Ershov, M. M. Shultz, Neorg. Mater. 10, 3 (1974) 572.

[26] K. K. Evstropiev, Opt. Mekh. Prom. 5, 1 (1963) 38.

[27] K. K. Evstropiev, V. K. Pavlovskii, Neorg. Mater. 3, 4 (1967) 673.

[28] F. M. Ezz Eldin, N. A. ElAlaily, Proc. $4^{\text {th }}$ Int. Conf. Fundamentals Glass Science and Technology, Sweden (1997) 506.

[29] G. H. Frischat, H. -E. Schutz, Glastech. Ber. 49, 7 (1976) 162.

[30] L. M. Gurikova, V. A. Zheleztsov, Steklo 1, 1 (1977) 39. [31] R. M. Hakim, D. R. Uhlmann, Phys. Chem. Glasses 8 , 5 (1967) 174.

[32] Y. Haven, B. Verkerk, Phys. Chem. Glasses 6, 2 (1965) 38.

[33] P. J. Hayward, Phys. Chem. Glasses 18, 1 (1977) 1.

[34] C. C. Hunter, M. D. Ingram, Solid State Ionics 14, 1 (1984) 31.

[35] V. A. Ioffe, Silikattechnik 10, 12 (1959) 599.

[36] V. V. Ipatjeva, Thesis, Leningrad (1968).

[37] J. O. Isard. Thesis, Sheffield (1962).

[38] A. O. Ivanov, Opt. Mekh. Prom. 10, 1 (1965) 29.

[39] T. N. Keshishyan, O. M. Smirnova, E. A. Fainberg, B.
G. Varshal, Neorg. Mater. 11, 5 (1975) 933.

[40] S. Sh. Kirakosyan, Stekloobraznoe Sostoyanie, Erevan (1974) 78.

[41] G. H. Kucera, I. Bloom, M. F. Roche, J. Electrochem. Soc. 133, 10 (1986) 1996.

[42] L. Yu. Kurts, Izv. Akad. Nauk SSSR, Otd. Khim. Nauk 4-5 (1941) 593.

[43] J. C. Lapp, PhD Thesis, Alfred, N.Y. (1986).

[44] V. K. Leko, Neorg. Mater. 3, 7 (1967) 1224.

[45] B. Lengyel, Glastech. Ber. 18, 7 (1940) 177.

[46] L. Guangyuan, M. Xingyi, L. Yuemei, W. Qitai, S. Shanding,

Proc. XVII Int. Cong. Glass, Beijing 5 (1995) 533.

[47] C. Lim, D. E. Day, J. Am. Ceram. Soc. 60, 5-6 (1977) 198.

[48] T. M. Makarova, V. S. Molchanov, Opt. Mekh. Prom. 2 (1961) 26.

[49] W. E. Martinsen, T. D. McGee, J. Am. Ceram. Soc. 54 (1971) 175.

[50] K. Matusita, S. Takayama, S. Sakka, J. Non-Cryst. Solids 40, 1-3 (1980) 149.

[51] O. V. Mazurin, R. V. Brailovskaya, Fizika Tverdogo Tela 2 (1960) 1477.

[52] O. V. Mazurin, E. S. Borisovskii, Zh. Tekhn. Fiz. 27 (1957) 275.

[53] O. V. Mazurin, G. T. Petrovskii, Tr. Leningr. Tekhnol. Inst. (1956) 30.

[54] I. G. Melnikova, A. Ya. Kuznetsov, V. A. Brinberg, Zh. Fiz. Khim. 24, 11 (1950) 1294.

[55] V. V. Moiseev, V. A. Zhabrev, Neorg. Mater. 5, 5 (1969) 934.

[56] H. Namikawa, J. Ceram. Soc. Jpn 83, 10 (1975) 500.

[57] G. D. Negodaev, I. A. Ivanov, K. K. Evstropiev, Neorg. Mater. 8, 2 (1972) 342.

[58] A. S. Nowick, B. S. Lim, A. V. Vaysleyb, J. Non-Cryst. Solids 172-174, 2 (1994) 1243.

[59] K. Otto, M. E. Milberg. J. Am. Ceram. Soc 51, 6 (1968) 326.

[60] T. Pagnier, J. L. Souquet, M. Ribes, Mater. Res. Bull. 20, 2 (1985) 225.

[61] G. A. Pavlova, Tr. Leningr. Tekhnol. Inst. 46, 1 (1958) 56.

[62] P. Pernice, A. Aronne, J. Mater. Sci. Lett. 10, 5 (1991) 297.

[63] G. T. Petrovskii, Silikaty 3, 4 (1959) 336.

[64] G. T. Petrovskii, Silikaty 4, 2 (1960) 118.

[65] R. S. Prasad, J. O. Isard, Phys. Chem. Glasses 8, 6 (1967) 218.

[66] A. A. Pronkin, Fizika i Khimiya Stekla 5, 5 (1979) 634.

[67] M. A. Rana, R. W. Douglas, Phys. Chem. Glasses 2, 6 (1961) 196.

[68] S. K. Saha, D. Chakravorty, J. Phys. D: Appl. Phys. 23, 9 (1990) 1201.

[69] E. Seddon, E. J. Tippet, W. E. S. Turner, J. Soc. Glass Technol. 16, 64 (1932) 450.

[70] S. W. Strauss, J. Res. Nat. Bur. Stand. 56, 4 (1956) 183.

[71] H. E. Taylor, Trans. Faraday Soc. 52, 6 (1956) 873.

[72] R. Terai, J. Ceram. Soc. Jpn. 77, 9 (1969) 318. 
[73] M. Tomozawa, M. Yoshiyagawa, Glastech. Ber. 56K, Bd2 (1983) 939.

[74] J. A. Topping, J. O. Isard, Phys. Chem. Glasses 12, 6 (1971) 145.

[75] V. A. Tsekhomskii, O. V. Mazurin, K. K. Evstropiev, Fizika Tverdogo Tela, Leningrad 5, 2 (1963) 586.

[76] H. Unuma, K. Komori, S. Sakka, J. Non-Cryst. Solids 95-96, 2 (1987) 913.

[77] D. Uschakow, M. Sorina, Sprechsaal 103, 20 (1970) 955.

[78] V. I. Vakhrameev, K. S. Evstropiev, Neorg. Mater 5, 1 (1969) 101.

[79] V. V. Vargin, E. A. Antonova, Zh. Prikl. Khim. 29, 11 (1956) 1749.

[80] H. Wakabayashi, R. Terai, H. Watanabe, J. Ceram. Soc. Jpn 94, 7 (1986) 677.

[81] M. Yoshiyagawa, M. Tomozawa, Solid State Ionics 23, 4 (1987) 271.

[82] I. I. Zhitkyavichyute, V. S. Molchanov, F. K. Aleinikov, Tr. An Lit. SSR B 2 (1965) 137.

[83] S. W. Martin, C. A. Angell, J. Non-Cryst. Solids 83, 1-2 (1986) 185.

[84] D. K. McElfresh, D. G. Howitt, J. Am. Ceram. Soc. 69, 10 (1986) C237.

[85] A. A. Appen, E. I. Kozlovskaya, Gan Fuxi, Zh. Prikhl. Khim. 34, 1 (1961) 975.

[86] M. H. Manghnani, B. K. Singh, Proc. $X^{\text {th }}$ Inter. Cong. Glass, Kyoto (1974) 104.

[87] G. O. Karapetian, V. Y. Livshits, D. G. Tennisson, Fiz. Khim. Stekla 7, 1(1981) 188.

[88] K. Takahashi, A. Osaka, J. Ceram. Soc. Jpn. 91, 1 (1983) 116.

[89] P. M. Halleck, R. E. Pacalo, E. K. Graham, J. Non-
Cryst. Solids 86, 1-2 (1986) 190.

[90] R. J. Eagan, J. C. Swearengen, J. Am. Ceram. Soc. 61, 1-2 (1978) 27.

[91] D. G. Tennison, PhD Thesis, Leningrad (1981).

[92] V. Y. Livshits, D. G. Tennisson, S. B. Gukasyan, K. A. Kostanyan, Fiz. Khim. Stekla 8, 1 (1982) 688.

[93] V. A. Molot, M.Sc. Thesis (1992).

[94] K. Matusita, S. Sakka, K. Osaka, N. Soga, M. Kunugi, J. Non-Cryst. Solids 16, 2 (1974) 308.

[95] G. F. Stockdale, Univ. III Bull. 50 (1953) 411.

[96] A. A. Appen, Gan Fuxi, Fizika Tverdogo Tela 1, 1 (1959) 1529.

[97] H. E. Taylor, Trans. Faraday. Soc. 52, 6 (1956) 873.

[98] H. Unuma, S. Sakka, J. Mater. Sci. Lett. 6, 9 (1987) 996.

[99] F. Keller, Z. Techn. Physik 13, 1 (1932) 237.

[100] Origin 7.0 (http://www.originlab.com).

[101] M. Takata, M. Tomozawa, E. B. Watson, J. Am. Ceram. Soc. 65, 9 (1982) 91.

[102] J. Swenson, L. Börjesson, Phys. Rev. Lett. 77, 17 (1996) 3569.

[103] J. Swenson, S. Adams, Phys. Rev. B 64, 2 (2002) 024204.

[104] S. Adams, J. Swenson, Solid State Ionics 154/155, 2 (2002) 151.

[105] M. L. F. Nascimento, S. Watanabe, J. Mater. Sci. 40 (2005) 4423.

[106] M. L. F. Nascimento, S. Watanabe, J. Mat. Sci. 40 (2005) 5079.

[107] S. Adams, J. Swenson, Phys. Rev. Lett. 84, 18 (2000) 4144.

(Rec. 16/03/2005, Ac. 30/09/2005) 